\title{
CCR4 ligands are up-regulated in the airways of atopic asthmatics after segmental allergen challenge
}

\author{
C. Pilette*, J.N. Francis*, S.J. Till, S.R. Durham
}

\begin{abstract}
CCR4 ligands are up-regulated in the airways of atopic asthmatics after segmental allergen challenge. C. Pilette, J.N. Francis, S.J. Till, S.R. Durham. C)ERS Journals Ltd 2004.
\end{abstract}

ABSTRACT: T-helper (Th) 2 cytokines are thought to mediate most features of allergic inflammation in atopic asthma. However, it remains unclear whether chemokine pathways direct selective recruitment of $\mathrm{Th} 2$ cells to the airways during human allergic responses.

Bronchoalveolar lavage (BAL) was performed in 15 nonsmoking mild atopic asthmatics before and $24 \mathrm{~h}$ after a fibreoptic segmental allergen challenge, and chemokines related to T-cell recruitment were assayed by ELISA.

The Th2-related C-C chemokine (CCR)4 ligands, macrophage-derived chemokine/C$\mathrm{C}$ chemokine ligand (CCL)22 and thymus and activation-regulated chemokine/CCL17, were increased in BAL after challenge. These chemokines correlated significantly with lymphocyte numbers and with interleukin (IL)-5 and IL-13 in post-challenge BAL. In contrast, two out of three putative Th1-related chemokines did not change. There were no alterations in monokine induced by interferon (IFN)- $\gamma / \mathrm{CXC}$ chemokine ligand (CXCL)9 or macrophage inflammatory protein-1 $/$ /CCL3; whereas a significant increase in IFN-induced protein-10kDa/CXCL10 was observed, which did not correlate with the T-cell influx. In peripheral mononuclear cells from atopic donors, CCL22 and CCL17 were induced by IL-4 and IL-13, further supporting the relationship between CCL22/CCL17 and Th2 cytokines. Finally, CCL22 was able to trigger actin polymerisation in peripheral CD4+ T-cells expressing CCR4.

Thus, C-C chemokine receptor 4 ligands are up-regulated in the airways of atopic asthmatics following allergen exposure, contribute to the $T$-cell influx to the airways and are closely related to the $\mathbf{T h 2}$-cytokine response.

Eur Respir J 2004; 23: 876-884.
Upper Respiratory Medicine, Imperial College London, National Heart \& Lung Institute, London, UK.

Correspondence: S.R. Durham, Upper Respiratory Medicine, Imperial College, National Heart \& Lung Institute, Dovehouse Street, London, SW3 6LY, UK. Fax: 442073518949

E-mail: s.durham@imperial.ac.uk

Keywords: Allergen challenge asthma

C-C chemokine receptor 4 chemokines

cytokines

Received: September 102003

Accepted after revision: January 62004

C. Pilette is supported by a research fellowship from the European Respiratory Society, Lausanne, Switzerland (ERS; Grant No. LTRF2002-037). This work was supported by a grant from the National Asthma Campaign UK and financial support from GlaxoSmithKline (for the salary of J.N. Francis).

*Authors contributed equally to this study.
Tissue infiltration by $\mathrm{T}$-cells that are polarised towards a T-helper (Th) 2 phenotype has emerged as an important feature of asthma and related allergic disorders [1]. Thus, T-cells producing specific cytokines (interleukin (IL)-4, IL-5, IL-9 and IL-13) are crucial for immunoglobulin (Ig)E synthesis, mucus production, the recruitment and activation of eosinophils and mast cells, and for the development of airway hyperresponsiveness (AHR) [2]. Although induction of the expression of Th2 cytokines during late asthmatic responses has been documented in several studies [3-6], the profile of the chemokine response to allergen challenge has been only partly defined in atopic asthma.

It has been shown that eotaxin is rapidly induced after allergen challenge in seasonal asthmatics, and correlates with the number of airway eosinophils [7]. The eotaxin receptor, C-C chemokine receptor (CCR)3, is expressed by eosinophils and basophils, but at a very low level on activated human T-cells in vivo $[8,9]$. In addition to CCR3, CCR4 and CCR8 have been associated with the Th2 phenotype [10]. More specifically, the CCR4 pathway has been proposed to mediate the allergen-induced recruitment of T-lymphocytes to the airway in mice $[11,12]$ and humans $[9,13]$. However, the expression profile of Th2 versus Th1 chemokines, with regard to influx of T-lymphocytes to the airway, has not yet been evaluated in the same study during human late asthmatic responses. It therefore remains unclear whether the chemokine response of the airways from atopic asthmatics to allergen exposure is polarised towards a Th2 type, and to what extent this response is associated with the Th2-cytokine response.

The current authors have previously shown that gene expression of CCR4, assessed by in situ hybridisation, is upregulated in bronchial tissue from challenged atopic asthmatics [13]. Moreover, CCR4 expression correlated with the T-cell infiltration induced after allergen challenge. The aim of the present study was to evaluate, in atopic asthma, the allergen-induced changes in the bronchial expression of ligands for chemokine receptors expressed by T-cells and, more specifically, those associated with Th2 versus Th1 responses. Therefore, the current authors assessed Th2- and Th1-related chemokines in the bronchoalveolar lavage (BAL) fluid recovered before and after local endobronchial allergen challenge of atopic asthmatics. The authors also evaluated the chemokine response to allergen challenge in healthy, nonatopic control subjects. Macrophage-derived chemokine /C-C chemokine ligand (CCL)22, thymus and activation-regulated chemokine/CCL17 (CCR4 ligands) and I-309/CCL1 (CCR8 ligand) represented Th2-related chemokines, while putative Th1 chemokines consisted of macrophage inflammatory protein$1 \alpha /$ CCL3 (ligand for CCR 1 and CCR5), monokine induced by interferon (IFN)- $\gamma / \mathrm{CXC}$ chemokine ligand (CXCL) 9 and IFN-inducible protein-10 kDa (IP-10)/CXCL10 (CXC chemokine receptor (CXCR)3 ligands). Chemokine pathways 
related to T-cells, irrespective of their Th2/Th1 phenotype (CCR6-7, CXCR1-2-4-6, CX ${ }_{3}$ CR1) [14], were not assessed. The relationship between the chemokine response and Th2 cytokines (IL-4, IL-5, IL-13) was investigated in vivo. In order to further evaluate the association between the chemokine and cytokine responses, the current authors assessed, in vitro, the regulation of chemokine production by cytokines in peripheral blood mononuclear cells (PBMC) from atopic donors. Finally, the authors evaluated the responsiveness of circulating, blood T-cells to CCR4 ligands using actin polymerisation as functional readout $[15,16]$.

\section{Materials and methods}

\section{Patient characterisation}

Fifteen nonsmoking atopic subjects with a clinical history of house dust mite- or grass pollen-sensitive asthma, as defined by the American Thoracic Society criteria, took part in the study. All patients, aged 18-55 yrs, were required to have baseline forced expiratory volume in one second (FEV1) $>80 \%$ predicted and methacholine provocative concentration causing a $20 \%$ fall in FEV1 $<32 \mathrm{mg} \cdot \mathrm{mL}^{-1}$ but $>0.5 \mathrm{mg} \cdot \mathrm{mL}^{-1}$. All subjects were also required to have $>5-\mathrm{mm}$ diameter weal at 15 min after skin-prick testing with house dust mite (Dermatophagoides pteronyssinus) or timothy grass pollen (Phleum pratense) extracts (Soluprick; ALK Abello, Horsholm, Denmark) in the presence of negative diluent and positive histamine controls, and serum specific IgE antibodies (detected by radioallergosorbent test (RAST)) to the same allergen. Subjects were excluded if they had received systemic glucocorticosteroids within the past 6 months or allergen immunotherapy within the previous 5 yrs. In addition, inhaled corticosteroids were discontinued for $\geqslant 2$ weeks before the allergen challenge. Patient characteristics (allergen sensitivity, late-phase response) are shown in table 1. In addition, four healthy, nonatopic and nonsmoking volunteers (aged 18-55 yrs, with negative skin and RAST tests to common aeroallergens) were included as a control group. The study was performed with the approval of the Ethics Committee of the Royal Brompton and Harefield Hospitals
NHS Trust and the written informed consent of all the participants.

\section{Fibreoptic endobronchial allergen challenge}

The procedure for bronchoscopy, BAL and segmental allergen provocation was as previously described [6]. During an initial endoscopy, BAL was taken from the right upper lobe and 500 biological units (100 units first and, after 5 min, 400 units in the absence of excessive local bronchoconstriction) of the relevant allergen (D. pteronyssinus or $P$. pratense as respective major allergens for house dust mite and grass pollen, according to the clinical history and skin-prick tests), diluted in sterile saline, were instilled in the middle lobe. All controls were challenged with $P$. pratense. BAL was obtained $24 \mathrm{~h}$ later from the challenged middle lobe segment. FEV1 was carefully monitored for at least $8 \mathrm{~h}$ and 22-24 h after the allergen challenge procedure. Inhaled

$\beta_{2}$-agonists were administered as required. The maximal fall in FEV1 $>4 \mathrm{~h}$ after the allergen challenge was used to define the clinical late-phase response.

\section{Processing of bronchoalveolar lavage fluid}

BAL samples were filtered through sterile gauze and centrifuged. Cytospins were prepared from resuspended cells and BAL supernatants were divided into 1-mL aliquots stored at $-80^{\circ} \mathrm{C}$ until analysis. Total and differential cell counts were performed on methanol-fixed cytospins of BAL cells after May-Grünwald and Giemsa staining.

\section{Peripheral blood mononuclear cell cultures}

PBMC were isolated from heparinised blood of atopic donors by centrifugation over Histopaque. Mononuclear cells were washed twice in RPMI-1640 medium and resuspended in RPMI-1640 supplemented with $2 \mathrm{mM}$ L-glutamine, 5\% human serum, $100 \mathrm{U} \cdot \mathrm{mL}^{-1}$ penicillin and $100 \mu \mathrm{g} \cdot \mathrm{mL}^{-1}$ streptomycin. PBMC were then incubated at $1 \times 10^{6}$ cells $^{-}$well $^{-1}$ for $72 \mathrm{~h}$ in humidified atmosphere $\left(37^{\circ} \mathrm{C}, 5 \% \quad \mathrm{CO}_{2}\right)$ with $\mathrm{IL}-2$

Table 1.-Clinical and cellular late-phase responses to allergen challenge

\begin{tabular}{|c|c|c|c|c|c|c|c|}
\hline \multirow[t]{2}{*}{ Subject } & \multirow[t]{2}{*}{ Allergen } & \multirow[t]{2}{*}{ LPR } & \multicolumn{2}{|c|}{ Total cells } & \multicolumn{2}{|c|}{ Ly } & \multirow[t]{2}{*}{ Ly post/pre ratio } \\
\hline & & & Pre $\times 10^{6}$ & Post $\times 10^{6}$ & Pre $\times 10^{6}$ & Post $\times 10^{6}$ & \\
\hline 1 & HDM & 8 & 9.4 & 25.7 & 0.19 & 0.77 & 4.1 \\
\hline 2 & HDM & 22 & 7.1 & 66.5 & 0.21 & 7.32 & 34.9 \\
\hline 3 & HDM & 23 & 2.3 & 7.2 & 0.26 & 2.84 & 10.9 \\
\hline 4 & HDM & 31 & 5.6 & 25.6 & 0.22 & 2.05 & 9.3 \\
\hline 5 & GP & 33 & 1.3 & 32.0 & 0.11 & 3.52 & 32.0 \\
\hline 6 & GP & 21 & 1.1 & 12.0 & 0.06 & 1.20 & 20.0 \\
\hline 7 & GP & 12 & 22.5 & 70.0 & 1.12 & 6.98 & 6.2 \\
\hline 8 & GP & 19 & 6.0 & 15.9 & 0.54 & 1.43 & 2.6 \\
\hline 9 & GP & 12 & 6.0 & 19.8 & NA & 2.57 & NA \\
\hline 10 & HDM & 28 & 5.0 & 4.0 & 0.25 & 0.08 & 0.3 \\
\hline 11 & GP & 25 & 28.1 & 95.5 & 0.56 & 6.69 & 11.9 \\
\hline 12 & GP & 41 & 7.3 & 75.0 & 0.22 & 0.75 & 3.4 \\
\hline 13 & GP & 24 & 14.5 & 20.0 & 0.29 & 0.80 & 2.8 \\
\hline 14 & GP & 18 & 3.8 & 28.8 & 0.34 & 0.86 & 2.5 \\
\hline 15 & GP & 39 & 6.6 & 381.0 & 0.59 & 11.43 & 19.4 \\
\hline
\end{tabular}

Data are presented as $\mathrm{n}$. The bronchoalveolar lavage cell numbers are shown as the absolute counts before (pre) and after (post) challenge and, for lymphocytes (Ly), as their fold increase (post-pre-challenge ratio). HDM: house dust mite; GP: timothy grass pollen allergen; LPR: late-phase response (maximal fall in forced expiratory volume in $1 \mathrm{~s}>4 \mathrm{~h}$ after allergen challenge); NA: not available. 
$\left(10 \mathrm{ng} \cdot \mathrm{mL}^{-1}\right)$ and one of the following cytokines: IL-4, IL-5, IL-13 or IFN- $\gamma\left(20 \mathrm{ng} \cdot \mathrm{mL}^{-1}\right.$ for each). Phytohemagglutinin $\left(1 \mu \mathrm{g} \cdot \mathrm{mL}^{-1}\right)$ was used as a positive control. The supernatants were frozen at $-20^{\circ} \mathrm{C}$ until chemokine assessments.

\section{Chemokine and cytokine ELISA}

Chemokines and cytokines were measured in unconcentrated BAL and cell culture supernatants by ELISA, using specific pairs (capture and biotinylated-detection) of antibodies. Paired antibodies to CCL1, CCL3, CXCL9 and CXCL10 were from PeproTech (London, UK), as well as detecting antibodies to CCL17 and CCL22. Capture antibodies to CCL17 and CCL22 were from R\&D Systems (Abingdon, UK) and paired antibodies to IL-4, IL-5 and IL-13 from BD Pharmingen (Oxford, UK). IL-12 was detected using paired antibodies (PeproTech) to all subunits of the cytokine (p35, p40, p70).

Nunc microplates (96 well) (Life Technologies, Paisley, UK) were coated with the appropriate capture antibody and blocked with $1 \%$ weight/volume (w/v) bovine serum albumin (BSA)-phosphate buffered saline (PBS). BAL samples in duplicate and serial dilutions of recombinant chemokines/ cytokines (from Peprotech, except IL-5, which was from BD Pharmingen) were then incubated, before the appropriate biotinylated-detection antibody. The reaction was revealed by incubation with peroxidase-conjugated streptavidine, and developed with tetramethylbenzidine and hydrogen peroxide. Optical density was recorded at $450 \mathrm{~nm}$ and concentrations expressed in $\mathrm{pg} \cdot \mathrm{mL}^{-1}$. Detection limits were $5-10 \mathrm{pg} \cdot \mathrm{mL}^{-1}$ for CCL22, CCL1, CCL3, IL-4, IL-5, IL-13, IL-12 and IFN- $\gamma$, and $2 \mathrm{pg} \cdot \mathrm{mL}^{-1}$ for CCL17, CXCL9 and CXCL10. General laboratory reagents were obtained from Sigma (Poole, UK).

BAL chemokine data were corrected for protein plasma leakage [17] by measuring albumin concentration in BAL before/after challenge by a chemoluminescent immunoassay using the DPC Immunolyte analyser (EuroDPC Ltd, Llanberis, Wales, UK). For each chemokine, the ratio to albumin was calculated in BAL before/after segmental challenge.

\section{Actin polymerisation assay}

Freshly isolated PBMC were washed with staining buffer $(0.1 \% \mathrm{w} / \mathrm{v}$ BSA and $0.09 \% \mathrm{w} / \mathrm{v}$ sodium azide in PBS), resuspended at $5 \times 10^{6}$ cells $\cdot \mathrm{mL}^{-1}$ and incubated with $10 \mu \mathrm{g} \cdot \mathrm{mL}^{-1}$ of anti-CCR4-phycoerythrin (BD Pharmingen) and anti-CD4phycoerythrin-Cy5 (DakoCytomation, Ely, UK) for $30 \mathrm{~min}$. After washing for $10 \mathrm{~min}$ at $37^{\circ} \mathrm{C}$ in RPMI, either CCL22 or CCL17 at $10 \mathrm{ng} \cdot \mathrm{mL}^{-1}$ was added to the cell suspension; every $15 \mathrm{~s}, 0.5 \times 10^{6}$ cells were removed and mixed with $400 \mu \mathrm{L}$ of $10^{-7} \mathrm{M}$ FITC-labelled phalloidin, $0.125 \mathrm{mg} \cdot \mathrm{mL}^{-1} \mathrm{~L}-\alpha-$ lysophosphatidylcholine and 4\% paraformaldehyde (Sigma) in PBS. Fixed cells were analysed by flow cytometry using a dual laser FACScan (Becton-Dickinson, Mountainview, CA, USA) and WinMDI software (J. Trotter, The Scripps Research Institute, La Jolla, CA, USA).

\section{Statistical analysis}

Data obtained in BAL before and after allergen challenge, presented as median (interquartile range), were compared by the nonparametric Wilcoxon's match-paired test, and correlations were assessed by the Spearman's rank correlation test. Results of the cell-culture experiments presented as mean \pm SD were analysed by the paired t-test, and Bonferroni's correction was applied when multiple comparisons were performed with a same control condition.

\section{Results}

\section{Lymphocyte recruitment to the airway after allergen challenge of atopic asthmatics}

Endobronchial exposure to allergen was associated with highly significant elevations of the total number of cells, and of the number of lymphocytes $\left(3.28(0.08-11.43) \times 10^{6}\right.$, median (range), versus $\left.0.36(0.06-1.12) \times 10^{6}, \mathrm{p}<0.001\right)$, recovered $24 \mathrm{~h}$ later by BAL (table 1). Among the 10 asthmatics who developed a clinically significant late-phase response after challenge (as defined by $\geqslant 20 \%$ fall in FEV1), seven patients displayed $a \geqslant 10$-fold increase in BAL lymphocytes. In contrast, none of the five nonresponders showed such an increase in the number of BAL lymphocytes. No significant increase in BAL lymphocytes was observed after challenge in nonatopic controls (not shown), along with the absence of a significant clinical late-phase response in these healthy subjects.

\section{CCL22 and CCL17 are induced in bronchoalveolar lavage fluid after allergen challenge}

CCL22, which was consistently detected in BAL fluid supernatants from atopic asthmatics at baseline (fig. 1), was strongly increased in BAL $24 \mathrm{~h}$ after allergen challenge $(p<0.001)$. CCL17, the other ligand for CCR4, was also consistently induced after challenge $(\mathrm{p}<0.001)$. In contrast, CCL1 did not change in BAL after local exposure to the allergen.

Among the Th1-related chemokines CCL3, CXCL9 and CXCL10, only CXCL10 was significantly up-regulated in the lung from challenged asthmatics $(\mathrm{p}=0.004)$.

\section{CCL22 and CCL17 are locally produced after airway allergen challenge}

To confirm that chemokines induced in BAL are locally produced within the challenged airway, the current authors corrected the concentrations of chemokines for that of albumin or urea. BAL concentration of albumin was significantly increased after allergen challenge $(0.1(0.06-0.15)$ versus $\left.0.04(0.03-0.06) \mathrm{mg} \cdot \mathrm{mL}^{-1}, \mathrm{p}<0.001\right)$, relating to nonspecific leakage of plasma proteins into the bronchoalveolar space. BAL urea also tended to increase after challenge, but without reaching statistical significance $(0.4 \quad(0.4-0.5)$ versus 0.3 (0.2-0.3), $\mathrm{p}=0.07)$. The CCL22/albumin, CCL17/albumin and CXCL10/albumin ratios were also significantly increased after challenge, suggesting a local production within the airways, as supported by the absence of significant changes in the serum levels of these chemokines (data not shown).

\section{CCL22 and CCL17 correlate with the allergen-induced lymphocyte influx to the airway}

The level of CCL22 significantly correlated with the number of lymphocytes recovered in BAL after endobronchial allergen challenge (fig. 2). A similar correlation was observed for CCL17 (in responders: $r=0.62, p=0.02$ ). Additionally, in the 10 responders, CCL22 correlated with the lymphocyte influx to the airway in terms of fold increase. No 

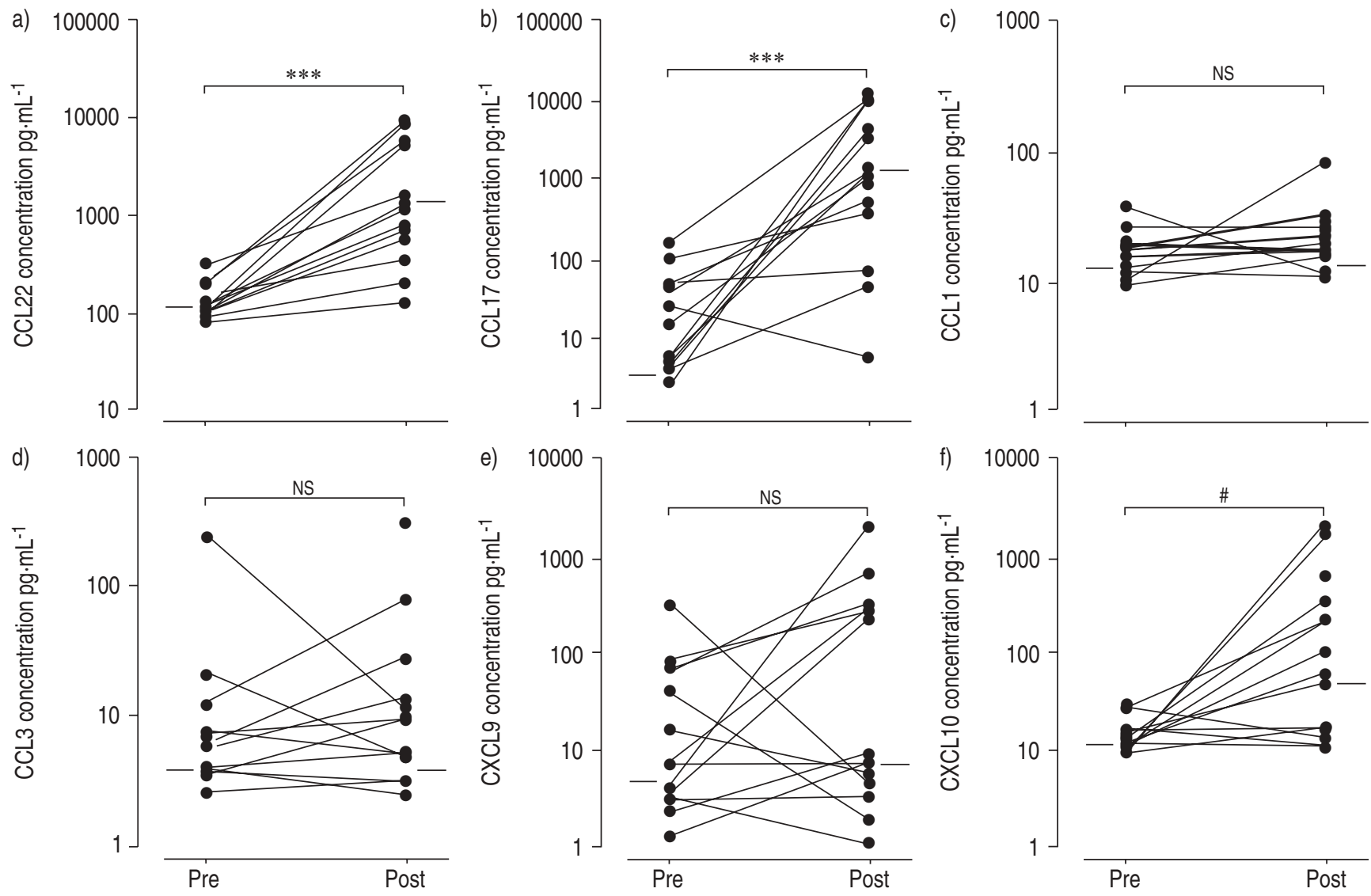

Fig. 1. - Chemokines in bronchoalveolar lavage (BAL) from atopic asthmatics $(n=15)$ during the late response to allergen challenge. T-helper (Th)2- (a) C-C chemokine ligand (CCL)22, b) CCL17, c) CCL1) and Th1-related chemokines (d) CCL3, e) CXC chemokine ligand (CXCL)9, f) CXCL10) were assessed by ELISA in BAL recovered before (pre) and $24 \mathrm{~h}$ after (post) segmental challenge with the relevant allergen. Paired data were compared using the Wilcoxon's match-paired test. ${ }^{* * *}: \mathrm{p}<0.001$; NS: nonsignificant; ${ }^{\#}: \mathrm{p}=0.004$.

significant correlation was observed between CCL22 or CCL17 and other cell types such as eosinophils (not shown), or between CXCL10 and the allergen-induced cellular influx to the airway. However, CXCL10 correlated with the clinical late-phase response $(\mathrm{r}=0.55, \mathrm{p}=0.04)$, especially in responders $(\mathrm{r}=0.65, \mathrm{p}=0.03)$.

\section{Th2 cytokines are up-regulated after allergen challenge}

In order to assess the relationship between the chemokine and cytokine responses after bronchial segmental allergen challenge, Th2 and Th1 cytokines were also measured. IL-5 and IL-13 were markedly increased in BAL from atopic
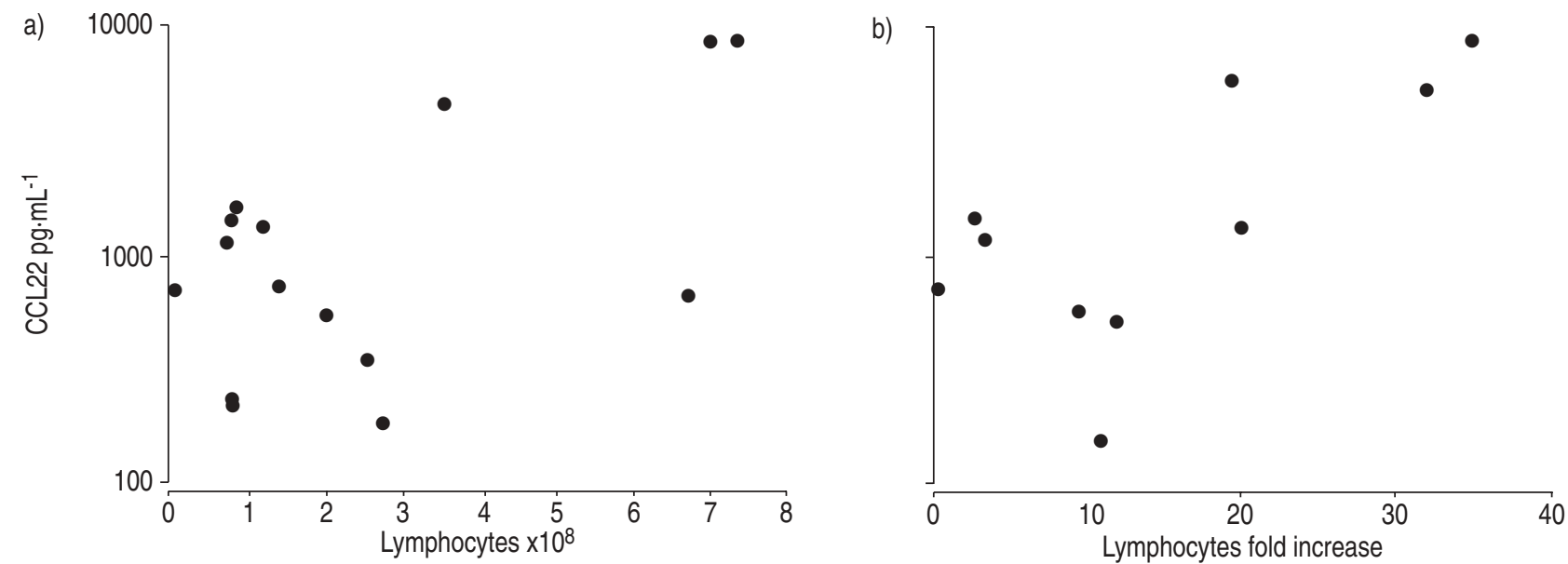

Fig. 2.-Correlation between C-C chemokine ligand (CCL) 22 and lymphocytes during the late asthmatic response. CCL22 was plotted against the number of lymphocytes in a) post-challenge bronchoalveolar lavage $(n=15, r=0.53, p=0.02)$ and $b)$ the fold increase in lymphocytes (ratio of postchallenge/pre-challenge lymphocytes, table 1 ) in asthmatics exhibiting a significant clinical late-phase response ( $=10$, $r=0.71$, $\mathrm{p}=0.01)$. $\mathrm{Statistical}$ significance was assessed using the Spearman's rank test. 

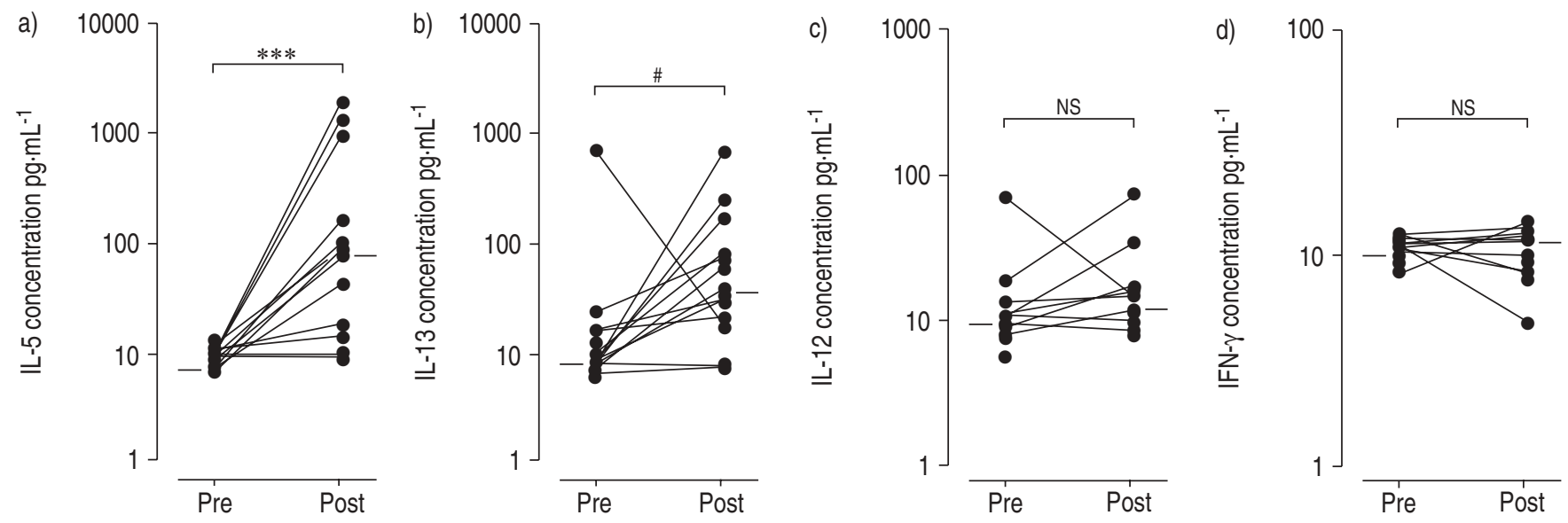

Fig. 3.-Cytokines in bronchoalveolar lavage (BAL) from atopic asthmatics during the late-phase response. T-helper (Th)2 (a) interleukin (IL)-5, b) IL-13) and Th1 cytokines (c) IL-12, d) interferon (IFN)- $\gamma$ ) were assessed by ELISA in BAL before (pre) and after (post) allergen challenge, and results were compared using the Wilcoxon's match-paired test. $* * *: \mathrm{p}<0.001$; ${ }^{\#}$ : $\mathrm{p}=0.002$; NS: nonsignificant.

asthmatics $24 \mathrm{~h}$ after allergen challenge, as compared to baseline (fig. $3 ; p<0.001$ and $p=0.002$, respectively). IL-4 remained just above the detection limit and did not change after challenge (data not shown). In contrast to Th2 cytokines, the levels of IFN- $\gamma$ and IL-12 remained unchanged after challenge.
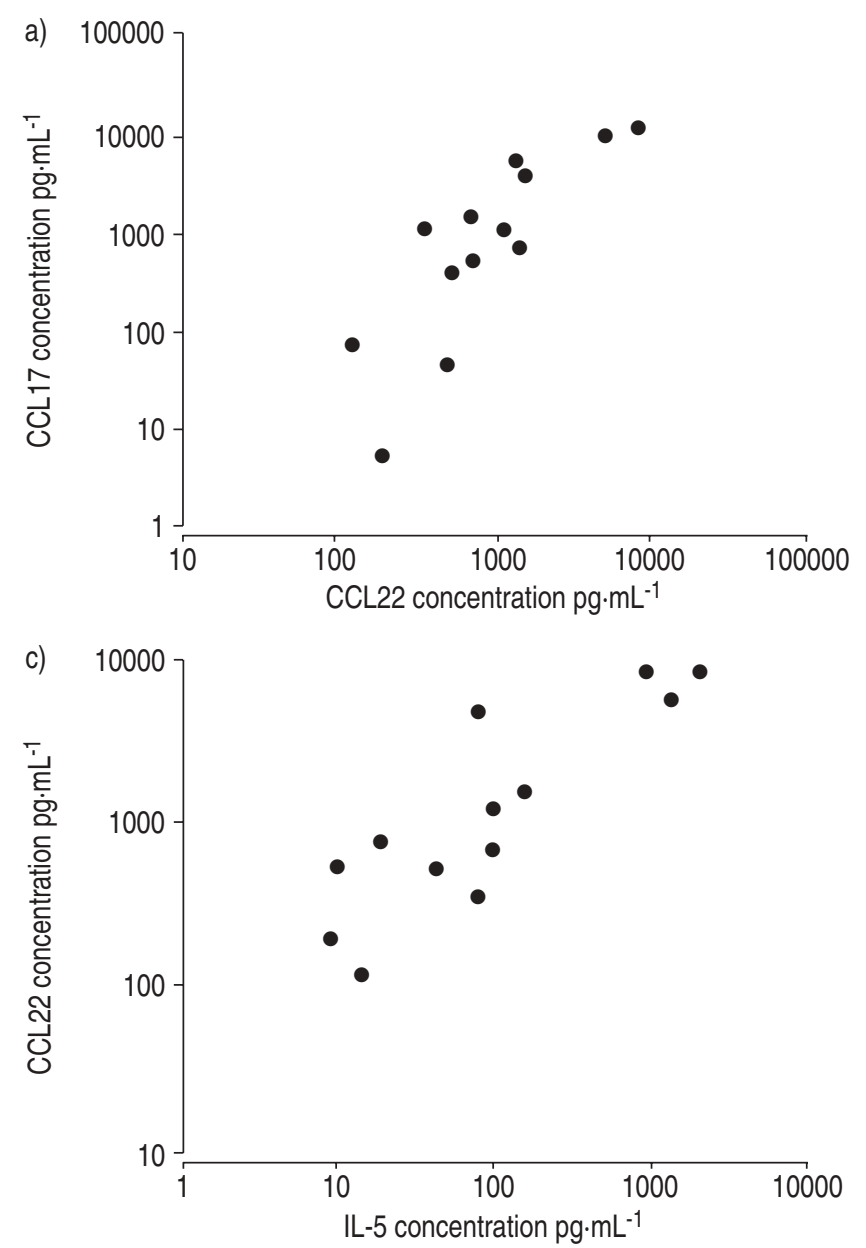

\section{CCL22 and CCL17 levels correlate with Th2 cytokines}

In post-challenge BAL, the level of CCL22 strongly correlated with CCL17 (fig. 4; r=0.89, p<0.001). CCL22 also strongly correlated with IL-5 and IL-13 (r=0.84 and 0.77,
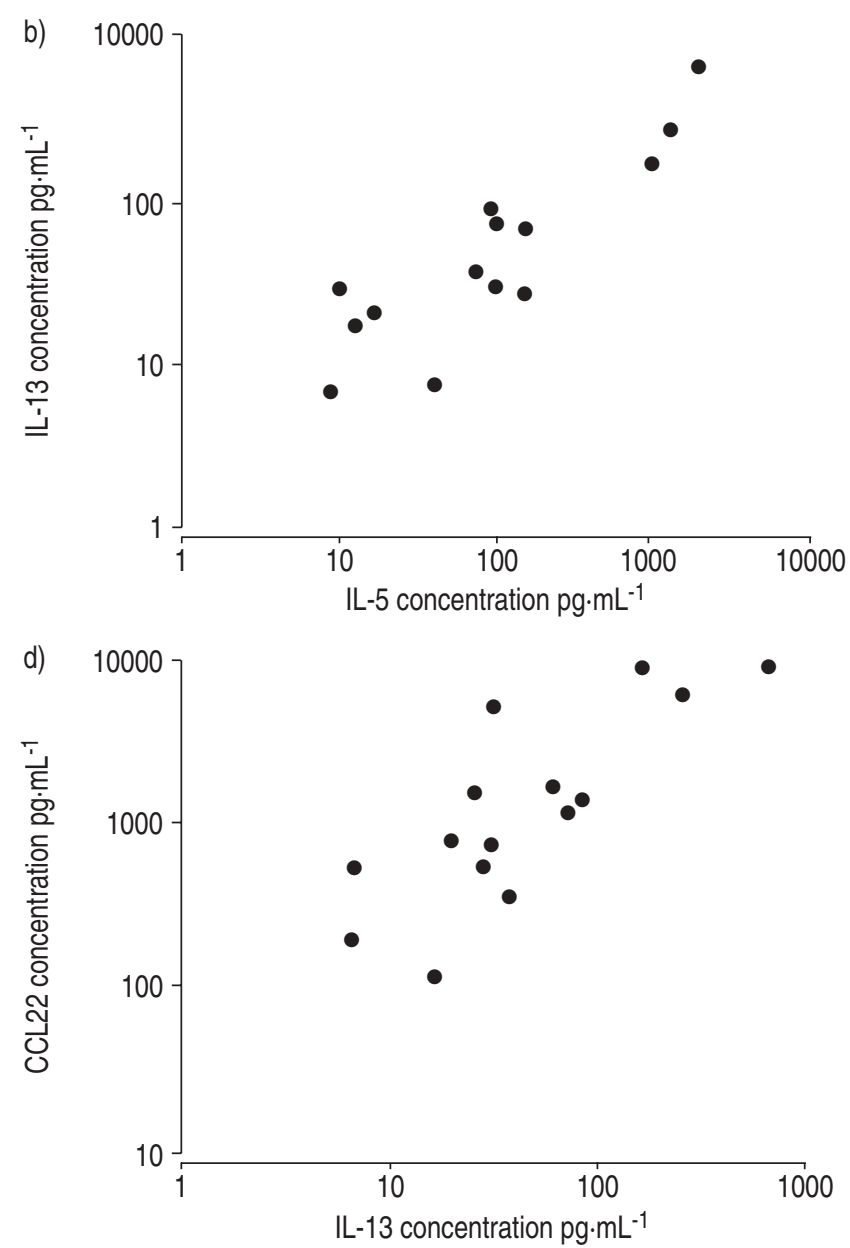

Fig. 4.-Relationship between T-helper (Th)2-related chemokines and Th2 cytokines during the late asthmatic response. a) C-C chemokine ligand (CCL) 22 was plotted against CCL17 ( $\mathrm{r}=0.89, \mathrm{p}<0.001)$, and b) interleukin (IL)-5 against IL-13 ( $\mathrm{r}=0.91$, $\mathrm{p}<0.001$ ), in bronchoalveolar lavage from challenged atopic asthmatics. c) IL-5 ( $\mathrm{r}=0.84, \mathrm{p}<0.001)$ and $\mathrm{d})$ IL-13 ( $\mathrm{r}=0.77, \mathrm{p}<0.001)$ were also plotted against CCL22. Correlations were assessed using the Spearman's rank test. 
respectively, $\mathrm{p}<0.001)$. CCL17 also correlated with the Th2 cytokines IL-5 and IL-13.

\section{CCL22 and CCL17 are not increased after allergen challenge in healthy controls}

In healthy, nonatopic controls no significant increase was observed in CCL22 or CCL17 after segmental allergen challenge (table 2). CXCL10 remained below the detection limit including after challenge. In fact, none of the measured chemokines was significantly increased in post-challenge BAL of the nonatopic, healthy controls.

\section{CCL22 and CCL17 are up-regulated in vitro by Th2 cytokines}

The current authors hypothesised that the correlation between CCL22/CCL17 and Th2 cytokines could be due to the up-regulation of their production by mononuclear cells, upon activation by $\mathrm{Th} 2$ cytokines. To address this hypothesis, the production of chemokines by PBMC cultured in the presence of Th 2 cytokines was assessed, as compared to IFN- $\gamma$. Production of CCL22 and CCL17 by cultured mononuclear cells was consistently induced in the presence of IL-4 or IL-13 (fig. 5), and IFN- $\gamma$ down-regulated the constitutive production of CCL22. In contrast, CCL1 did not display this Th2type pattern of regulation.

As expected, production of CXCL10 by PBMC was induced by IFN- $\gamma$ (fig. 5), and was down-regulated by IL-13 (and to a lesser extent by IL-4). CXCL9 exhibited the same pattern of regulation as CXCL10, whereas CCL3 was not significantly increased by IFN- $\gamma$.

\section{CCL22 and CCL17 induce actin polymerisation in T-lymphocytes}

The current authors performed experiments to determine whether the CCL22/CCR4 and CCL17/CCR4 pathways are active in circulating T-cells. The functional readout was actin polymerisation in response to stimulation with CCL22 and CCL17. CCR4 expression was observed on $32.05 \pm 1.54 \%$ (mean \pm SEM) of peripheral blood CD4+ T-cells from atopic donors $(n=5)$. CCR4-expressing blood CD4+ T-cells, incubated with $10 \mathrm{ng} \cdot \mathrm{mL}^{-1}$ CCL22, exhibited 2 -fold increase in polymeric filamentous F-actin immediately after $15 \mathrm{~s}$ of stimulation (fig. 6). A significant change in the cytoskeletal organisation of T-cells was also observed with CCL17, although this signal was to a lower extent than that observed with CCL22.

Table 2. - Bronchoalveolar lavage (BAL) chemokines before/ after allergen challenge in control subjects

Chemokine pg $\cdot \mathrm{mL}^{-1} \quad$ Pre-challenge BAL Post-challenge BAL

\begin{tabular}{lcc}
\hline CCL22 & $0(0-15.1)$ & $2.8(0-7.8)$ \\
CCL17 & $23.7(12.5-38.9)$ & $24.1(19.8-28.3)$ \\
CCL3 & $0.0(0.0-0.0)$ & $0.0(0.0-11.9)$ \\
CXCL10 & $0.0(0.0-0.0)$ & $0.0(0.0-0.0)$ \\
\hline
\end{tabular}

Data are presented as median (interquartile range). Chemokine concentrations were determined in BAL supernatants obtained before (pre-challenge) and $24 \mathrm{~h}$ after (post-challenge) segmental allergen challenge of nonatopic control subjects $(n=4)$ by ELISA. CCL: C-C chemokine receptor; CXCL: CXC chemokine ligand.

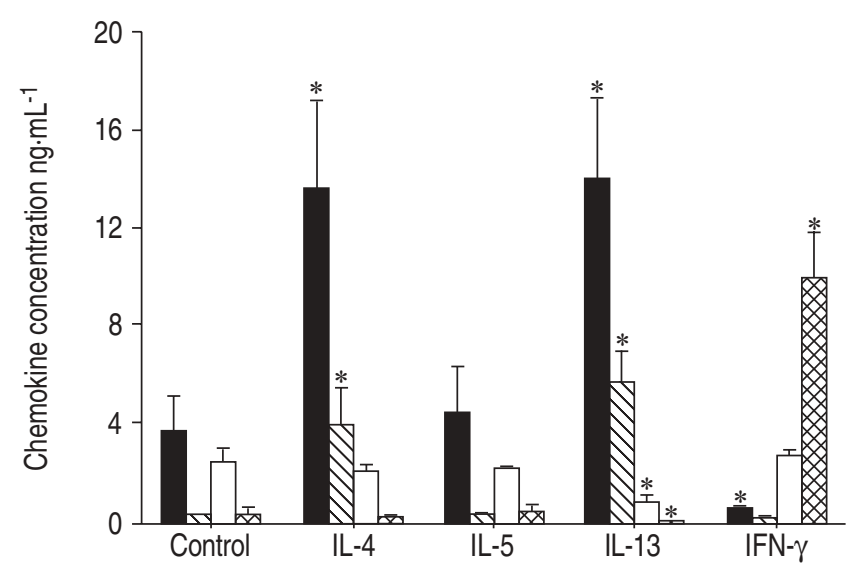

Fig. 5.-Regulation of chemokine production by T-helper (Th)2 cytokines and interferon (IFN)- $\gamma$ in peripheral blood mononuclear cells $(\mathrm{PBMC})$ from atopic donors $(n=3)$. Th2- $(\mathrm{C}-\mathrm{C}$ chemokine ligand (CCL)22, CCL17 and CCL1) and Th1-related chemokines (CXC chemokine ligand (CXCL)10) were measured by ELISA in supernatants from PBMC cultured for $72 \mathrm{~h}$ in the presence of interleukin (IL)-4, IL-5, IL-13 or IFN- $\gamma$ (each at $20 \mathrm{ng} \cdot \mathrm{mL}^{-1}$ ). Results (mean \pm SD) were compared with cells incubated with medium using the paired t-test and are representative of three independent experiments. Values for CCL1 are expressed 10-fold. $\square$ : CCL22; $\mathbb{8}$ : CCL17; $\square$ : CCL1; CXCL10. *: $\mathrm{p}<0.05$, as compared with control.

\section{Discussion}

The current authors and others have previously documented that CCR4 is up-regulated in the asthmatic airway after allergen challenge [9, 13]. This study shows that the ligands for CCR4 are also strongly up-regulated during the late response in atopic asthma. CCL22 and CCL17 levels were increased in the BAL fluid recovered $24 \mathrm{~h}$ after endobronchial allergen challenge of atopic asthmatics, and significantly correlated with BAL lymphocytes to some extent, more particularly in patients developing a significant clinical late-phase

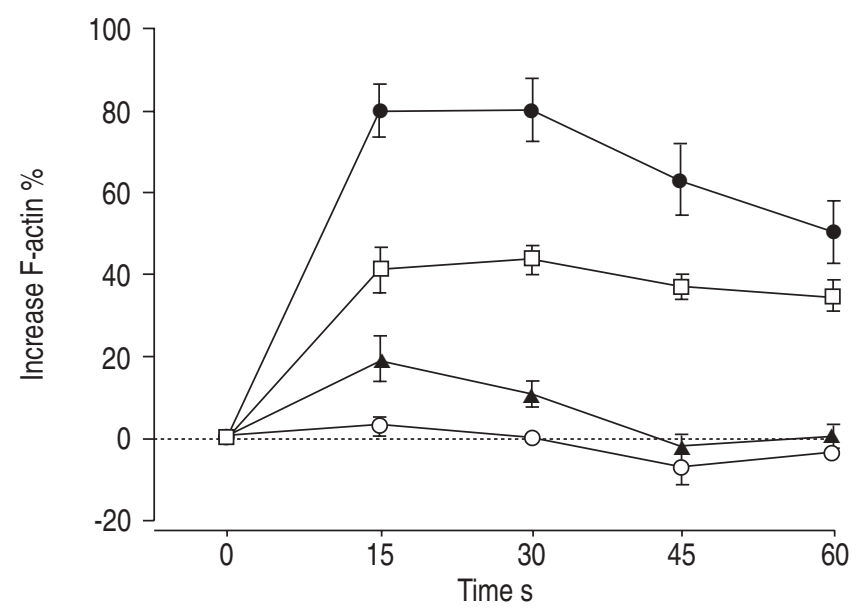

Fig. 6. - Induction of actin polymerisation in peripheral CD4+ T-cells by $\mathrm{C}-\mathrm{C}$ chemokine receptor (CCR)4 ligands. Blood T-lymphocytes from atopic subjects $(n=5)$ were incubated with $\mathrm{C}-\mathrm{C}$ chemokine ligand (CCL) 22 or CCL17 $\left(10 \mathrm{ng} \cdot \mathrm{mL}^{-1}\right)$ for the indicated times, and actin polymerisation was assessed after labelling with fluorescein isothiocyanate-phalloidin by flow cytometry. Results are expressed as the increase (as a percentage from baseline fluorescence) in mean fluorescence intensity of CD4+ T-cells. : $10 \mathrm{nM}$ macrophage-derived chemokine (CCL2) CCR4+; $\square$ : $10 \mathrm{nM}$ thymus and activationregulated chemokine (CCL17) CCR4+; $\boldsymbol{\Delta}$ : 10 nM CCL2 CCR4-; $\bigcirc$ : 10 nM CCL17 CCR4-. 
response. Moreover, the current authors observed, for the first time in vivo, that CCL22 and CCL17 strongly correlated with IL-5 and IL-13, which were also induced in BAL upon challenge. CCL22 and CCL17 were not induced upon segmental allergen challenge in nonatopic, healthy controls. In addition, expression of CCL22 and CCL17 in PBMC from atopic subjects was induced by IL-4 and IL-13, further supporting the idea that CCR4 ligands are closely related to the Th2-cytokine response. Among Th1-related chemokines, only CXCL10 was significantly increased in post-challenge BAL of asthmatics, and did not correlate with the T-cell influx in to the airway. Finally, the current authors observed that CCR4 is functionally active on circulating $\mathrm{T}$-cells in response to both chemokine ligands.

In asthma, once T-cells have been activated by cognate interactions with antigen-presenting cells, they re-circulate in the bloodstream and may be recruited to the airways upon further allergen exposure/challenge. Although it remains controversial whether the Th2 differentiation occurs systemically (in the lymph nodes draining the airways) or locally, it has been suggested that circulating T-cells from atopic subjects are type 2-biased [18]. Since CCR4 appears selectively expressed on Th2 lymphocytes in vitro [10], the observation that CCL22 and CCL17 are strongly up-regulated in the airway after allergen challenge of atopic asthmatics, and correlate with BAL lymphocytes, is consistent with a selective recruitment of circulating Th2 cells. In contrast, CCL1 did not increase after challenge, in line with previous studies showing that CCR 8 is up-regulated after challenge of asthmatics to a much lower extent than CCR4 [9], and does not play a significant role in the long-term recruitment of $\mathrm{T}$-cells upon repeated allergen exposures in mice [12].

It has been proposed that the cytokine microenvironment, especially that provided by dendritic cells, plays an important role during sensitisation to determine the T-cell profile [19]. Similarly, the cytokine milieu of the inflamed asthmatic airway might represent an important factor to drive the tissue recruitment of blood Th2 cells upon further allergen exposure. This hypothesis is supported in the current study, which shows a strong correlation between airway production of CCR4-binding chemokines and Th2 cytokines during the late asthmatic response for the first time in vivo. In addition, the current authors show that in mononuclear cells from atopic subjects, the production of CCL22 and CCL17, in contrast with CCL1, is induced by IL-4 and IL-13. It is therefore tempting to speculate that, after allergen sensitisation, further allergen exposure stimulates the mucosal production of $\mathrm{Th} 2$ cytokines (by infiltrating T-cells and IgE-bearing leukocytes) that trigger the release of Th2-dependent chemokines, namely CCL22 and CCL17. These chemokines may, in turn, mediate a selective recruitment to the airway of circulating Th2 lymphocytes expressing CCR4. Both the induction of CCL22 and CCL17 by IL-4 or IL-13, and the selective attraction of Th2 cytokine-producing cells by these chemokines (as an amplification circuit), may account for the correlation observed in this study between the Th2-cytokine response and CCR4 ligands.

This study was not designed to identify the cellular source(s) of the chemokines released in the airways upon allergen challenge. The current authors' in vitro system was based on the fact that mononuclear cells (consisting of monocytes and lymphocytes) represent a major source of CCR4 ligands. However, alternative sources have been described, such as airway epithelial cells or smooth muscle cells. These findings using PBMC are in line with those of ANDREW et al. [20], showing that CCL22 is inducible in monocytes upon IL-4 or IL-13 stimulation, as observed in T-cells; while macrophages constitutively produce CCL22, which is further increased by IL- 4 and reduced by IFN- $\gamma$. It was shown that
CCL17 may also be produced by bronchial epithelial cells stimulated by tumour necrosis factor (TNF)- $\alpha$ and IFN- $\gamma$ [21]. Dendritic cells activated by TNF- $\alpha$ can produce CCL22 and CCL17, whilst producing CCL1 and CXCL10 when activated through Toll-like receptors [22]. CXCR3-binding chemokines including CXCL10 can be released by mononuclear cells and/or by activated bronchial epithelial cells [23], although less information is available regarding the regulation of production of CXCR3 ligands. Preliminary data, including information in the present study, confirm that production of CXCL10 is mainly dependent on IFN- $\gamma$, at least in peripheral mononuclear cells.

The current authors' finding that CXCL10 is also significantly up-regulated in atopic asthmatics upon airway allergen challenge may appear intriguing. CXCL10 has been mainly implicated in Th1-mediated diseases, such as sarcoidosis [24] or chronic obstructive pulmonary disease [25], which is consistent with the observation that CXCR3 (CXCL10 receptor) is predominantly expressed by Th1 cells [26]. However, recent studies have also indicated a role for CXCL10 in asthma. First, it has been reported that airway expression of CXCL10 is increased in human asthma [27] and in mice sensitised to ovalbumin [28]. Secondly, in murine models of asthma, a dual effect of CXCL10 has been identified on AHR and tissue eosinophilia [28, 29]. Thirdly, it was shown that CXCL10 is induced in keratinocytes by both Th1- and Th2derived supernatants [30]. In blood mononuclear cells from atopics, the authors observed in this study that CXCL10 expression is only dependent on IFN- $\gamma$ (and inhibited by IL-13), as observed for CXCL9. However, CXCL10 was not significantly correlated with IFN- $\gamma$ in the BAL from challenged asthmatics (not shown), as previously observed in mice [28], suggesting that other factors could trigger CXCL10 expression in vivo. Interestingly, in adoptive transfer experiments, STEPHENS et al. [31] showed that viral activation of Th1 cells can enhance subsequent recruitment of allergenspecific Th2 cells upon lung viral challenge. Moreover, it has been recently suggested that, in lymph nodes, Th2 cells can somehow influence T-cells located in the same microenvironment, including Th1 cells [32], indicating that the T-cell programme is flexible during developing immune responses and depends on signals provided locally. Taken together, these data suggest that CXCL10/CXCR3 might represent another chemokine pathway involved in asthma, but its role and relevance in humans remain to be determined. The fact that CCR4 ligands only modestly correlated with T-lymphocytes further suggests that other chemokine pathways are involved. Moreover, the CXCR3 axis might also play a role in asthma through actions on other cell types, such as $\gamma \delta$ T-cells [33] or mast cells [34], which express CXCR3 and respond to its ligands.

An alternative explanation regarding IP-10 up-regulation in asthma relates to the selective recruitment of $\mathrm{Th} 1$ cells. Thus, IFN- $\gamma$-producing Th1-type cells detected in peripheral blood of atopic patients have been suggested to also play a role in asthma $[35,36]$, especially during the symptomatic phases of the disease. It could be hypothesised that a Th2 orientation in asthma mainly characterises the immune response during the sensitisation process and the acute reaction to allergen exposure; whereas, chronic inflammation could be underlined by a less specific T-cell profile. This view is supported by the clinical observation that Th2- (e.g. allergens) and Th1- (e.g. viruses) driving factors may both represent triggers of asthma exacerbations.

Finally, it was observed that a consistent proportion $(\sim 30 \%)$ of circulating CD4+ T-lymphocytes express CCR4, in line with previous studies [37, 38]. Evaluation of actin polymerisation in circulating blood T-cells expressing CCR4 confirmed that these cells are functionally responsive to 
CCL22 and CCL17, and could migrate to the airways upon stimulation by these chemokines released locally after allergen exposure in atopic asthmatics.

In summary, this study further highlights the C-C chemokine receptor 4 pathway as mediating the recruitment of T-lymphocytes to the inflamed airway in atopic asthma. The ligands for C-C chemokine receptor 4: 1) are strongly upregulated within the airways from atopic asthmatics after allergen challenge; 2) contribute to the T-cell influx to the airways; and 3) are closely related to the T-helper 2-cytokine response. The C-C chemokine receptor 4 pathway could therefore participate in the mechanisms underlying a selective recruitment of circulating T-helper 2 cells to the airways. This study also shows that various chemokine pathways could be implicated and supports the idea that targeting several chemokine receptors may be appropriate [14] to dampen $\mathrm{T}$-cell infiltration in chronic asthma.

\section{References}

1. Busse WW, Rosenwasser LJ. Mechanisms of asthma. J Allergy Clin Immunol 2003; 111: S799-S804.

2. Larche M, Robinson DS, Kay AB. The role of $\mathrm{T}$ lymphocytes in the pathogenesis of asthma. J Allergy Clin Immunol 2003; 111: 450-463.

3. Bentley AM, Meng Q, Robinson DS, Hamid Q, Kay AB, Durham SR. Increases in activated T lymphocytes, eosinophils, and cytokine mRNA expression for interleukin-5 and granulocyte/macrophage colony-stimulating factor in bronchial biopsies after allergen inhalation challenge in atopic asthmatics. Am J Respir Cell Mol Biol 1993; 8: 35-42.

4. Robinson DS, Ying S, Bentley AM, et al. Relationships among numbers of bronchoalveolar lavage cells expressing messenger ribonucleic acid for cytokines, asthma symptoms, and airway methacholine responsiveness in atopic asthma. J Allergy Clin Immunol 1993; 92: 397-403.

5. Kroegel C, Julius P, Matthys H, Virchow JC Jr, Luttman W. Endobronchial secretion of interleukin-13 following local allergen challenge in atopic asthma: relationship to interleukin-4 and eosinophil counts. Eur Respir J 1996; 9: 899904.

6. Till SJ, Durham SR, Rajakulasingam K, et al. Allergeninduced proliferation and interleukin-5 production by bronchoalveolar lavage and blood $\mathrm{T}$ cells after segmental allergen challenge. Am J Respir Crit Care Med 1998; 158: 404- 411 .

7. Lilly CM, Nakamura H, Belostotsky OI, et al. Eotaxin expression after segmental allergen challenge in subjects with atopic asthma. Am J Respir Crit Care Med 2001; 163: 16691675 .

8. Annunziato F, Cosmi L, Galli G, et al. Assessment of chemokine receptor expression by human Th1 and Th2 cells in vitro and in vivo. J Leukoc Biol 1999; 65: 691-699.

9. Panina-Bordignon P, Papi A, Mariani M, et al. The C-C chemokine receptors CCR 4 and CCR 8 identify airway T cells of allergen-challenged atopic asthmatics. J Clin Invest 2001; 107: 1357-1364.

10. Sallusto F, Mackay CR, Lanzavecchia A. Selective expression of the eotaxin receptor CCR 3 by human T helper 2 cells. Science 1997; 277: 2005-2007.

11. Gonzalo JA, Pan Y, Lloyd CM, J, et al. Mouse monocytederived chemokine is involved in airway hyperreactivity and lung inflammation. J Immunol 1999; 163: 403-411.

12. Lloyd CM, Delanay $\mathrm{T}$, Nguyen $\mathrm{T}$, et al. CC chemokine receptor (CCR)3/eotaxin is followed by CCR4/monocytederived chemokine in mediating pulmonary $\mathrm{T}$ helper lymphocyte type 2 recruitment after serial antigen challenge in vivo. J Exp Med 2000; 191: 265-274.

13. Nouri-Aria KT, Wilson D, Francis JN, et al. CCR4 in human allergen-induced late responses in the skin and lung. Eur J Immunol 2002; 32: 1933-1938.

14. Sabroe I, Lloyd CM, Whyte MKB, Dower SK, Williams TJ, Pease JE. Chemokines, innate and adaptive immunity, and respiratory disease. Eur Respir J 2002; 19: 350-355.

15. Foussat A, Coulomb-L'Hermine A, Gosling $\mathrm{J}$, et al. Fractalkine receptor expression by $\mathrm{T}$ lymphocyte subpopulations and in vivo production of fractalkine in human. Eur J Immunol 2000; 30: 87-97.

16. Gallo SA, Finnegan CM, Viard M, et al. The HIV Envmediated fusion reaction. Biochim Biophys Acta 2003; 1614: 36-50.

17. Rennard SI, Basset G, Lecossier D, et al. Estimation of volume of epithelial lining fluid recovered by lavage using urea as marker of dilution. J Appl Physiol 1986; 60: 532-538.

18. Parronchi P, De Carli M, Manetti R, et al. Aberrant interleukin (IL)-4 and IL-5 production in vitro by CD4+ helper T cells from atopic subjects. Eur J Immunol 1992; 22: $1615-1620$.

19. Holt PG. Regulation of immune responses at mucosal surfaces: allergic respiratory disease as a paradigm. Immunology Cell Biol 1998; 76: 119-124.

20. Andrew DP, Chang MS, McNinch J, et al. STCP-1 (MDC) $\mathrm{CC}$ chemokine acts specifically on chronically activated $\mathrm{Th} 2$ lymphocytes and is produced by monocytes on stimulation with Th2 cytokines IL-4 and IL-13. J Immunol 1998; 161: 5027-5038.

21. Sekiya $\mathrm{T}$, Miyamasu $\mathrm{M}$, Imanishi $\mathrm{M}$, et al. Inducible expression of a Th2-type CC chemokine thymus- and activation-regulated chemokine by human bronchial epithelial cells. J Immunol 2000; 165: 2205-2213.

22. Schweitzer B, Roberts S, Grimwade B, et al. Multiplexed protein profiling on microarrays by rolling-circle amplification. Nat Biotechnol 2002; 20: 359-365.

23. Sauty A, Dziejman M, Taha RA, et al. The T cell-specific CXC chemokines IP-10, Mig, and I-TAC are expressed by activated human bronchial epithelial cells. J Immunol 1999; 162: 3549-3558.

24. Agostini C, Cassatella M, Zambello R, et al. Involvement of the IP-10 chemokine in sarcoid granulomatous reactions. J Immunol 1998; 161: 6413-6420.

25. Saetta $\mathrm{M}$, Mariani $\mathrm{M}$, Panina-Bordignon $\mathrm{P}$, et al. Increased expression of the chemokine receptor CXCR3 and its ligand CXCL10 in peripheral airways of smokers with chronic obstructive pulmonary disease. Am J Respir Crit Care Med 2002; 165: 1404-1409.

26. Loetscher M, Loetscher P, Brass N, Meese E, Moser B. Lymphocyte-specific chemokine receptor CXCR3: regulation, chemokine binding and gene localization. Eur $J$ Immunol 1998; 28: 3696-3705.

27. Miotto D, Christodoulopuolos $\mathrm{P}$, Olivenstein $\mathrm{R}$, et al. Expression of IFN-gamma-inducible protein; monocyte chemotactic proteins 1,3, and 4; and eotaxin in Th1- and Th2-mediated lung diseases. J Allergy Clin Immunol 2001; 107: 664-670.

28. Medoff BD, Sauty A, Tager AM, et al. IFN-gammainducible protein 10 (CXCL10) contributes to airway hyperreactivity and airway inflammation in a mouse model of asthma. J Immunol 2002; 168: 5278-5586.

29. Thomas MS, Kunkel SL, Lukacs NW. Differential role of IFN-gamma-inducible protein $10 \mathrm{kDa}$ in a cockroach antigen-induced model of allergic airway hyperreactivity: systemic versus local effects. J Immunol 2002; 169: 70457053.

30. Albanesi C, Scarponi C, Sebastiani S, et al. A cytokine-tochemokine axis between $\mathrm{T}$ lymphocytes and keratinocytes can favor Th1 cell accumulation in chronic inflammatory skin diseases. $J$ Leukoc Biol 2001; 70: 617-623.

31. Stephens R, Randolph DA, Huang G, Holtzman MJ, Chaplin DD. Antigen-nonspecific recruitment of Th2 cells to the lung as a mechanism for viral infection-induced allergic asthma. J Immunol 2002; 169: 5458-5467. 
32. Schipf A, Heilmann A, Boue L, Mossman H, Brocker T, Rocken M. Th2 cells shape the differentiation of developing $\mathrm{T}$ cell responses during interactions with dendritic cells in vivo. Eur J Immunol 2003; 33: 1697-1706.

33. Ferrero E, Biswas P, Vettoretto K, et al. Macrophages exposed to Mycobacterium tuberculosis release chemokines able to recruit selected leucocyte subpopulations: focus on gammadelta cells. Immunology 2003; 108: 365-374.

34. Brightling CE, Morgan AJ, Sherrif E, Wardlaw AJ, Bradding $\mathrm{P}$. Chemokine receptor expression by human lung mast cells. Eur Respir J 2003; A187.

35. Magnan AO, Mely LG, Camilla CA, et al. Assessment of the Th1/Th2 paradigm in whole blood in atopy and asthma.
Increased IFN-gamma-producing CD8(+) $\mathrm{T}$ cells in asthma. Am J Respir Crit Care Med 2000; 161: 1790-1796.

36. Cho SH, Stanciu LA, Begishivili T, Bates PJ, Holgate ST, Johnston SL. Peripheral blood CD4+ and CD8+ T cell type 1 and type 2 cytokine production in atopic asthmatic and normal subjects. Clin Exp Allergy 2002; 32: 1790-1796.

37. Andrew DP, Ruffing N, Kim $\mathrm{CH}$, et al. C-C chemokine receptor 4 expression defines a major subset of circulating nonintestinal memory $\mathrm{T}$ cells of both $\mathrm{Th} 1$ and Th2 potential. J Immunol 2001; 166: 103-111.

38. Kunkel EJ, Boisvert J, Murphy K, et al. Expression of the chemokine receptors CCR4, CCR5, and CXCR3 by human tissue-infiltrating lymphocytes. Am J Pathol 2002; 160: 347-355. 